Bentham OPEN

RESEARCH ARTICLE

\title{
Evaluation of Semen Quality in Type 2 Diabetes Mellitus Sudanese Patients Compared to Non-Diabetic Subjects
}

\author{
Negwan E. Ibrahim ${ }^{1}$, Mohammed Rida ${ }^{2}$ and AbdElkarim A. Abdrabo ${ }^{1, *}$ \\ ${ }^{\text {I}}$ Department of Clinical Chemistry, Faculty of Medical Laboratory Science, Al-Neelain University, Khartoum-Sudan \\ ${ }^{2}$ Dr.Elsir Abu-Elhassan Fertility Center, Khartoum, Sudan
}

\begin{abstract}
:
\section{Background:}

Diabetes leads to metabolic abnormalities. These abnormalities produce problems in a variety of organ systems such as ophthalmopathies, neuropathies, nephropathies, and vasculopathies. Infertility is common in diabetic patients, caused by abnormal semen.
\end{abstract}

\section{Objectives:}

This study was conducted to check semen quality in diabetic Sudanese patients.

\section{Method:}

This is a retrospective cross-sectional designed study. The data were collected in a period from January 2015 to February 2017 . A total of 600 individuals was included, 300 with type 2 diabetes mellitus and 300 apparently healthy as a non-diabetic. Semen analysis was performed according to WHO criteria.

\section{Results:}

Significant lower results were found in diabetic patients compared to non diabetic regarding the following parameters: volume of ejaculation $(p=0.047)$, percent motility $(p=0.001)$, percent normal morphology $(p=0.000)$, while there was no difference in the sperm count between diabetic and non-diabetic subjects.

\section{Conclusion:}

Semen of types 2 diabetes mellitus patients is of low volume, abnormal motility and morphology compared to non-diabetic subjects.

Keywords: Diabetes, Infertility, Semen, Sudan, Vaseulopathies, Non-diabetic.

\section{INTRODUCTION}

Infertility is a disease of the reproductive system defined by the failure to achieve a clinical pregnancy after 12 months or more of regular unprotected sexual intercourse [1]. Male infertility refers to a male's inability to cause pregnancy in a fertile female. In humans, it accounts for $40-50 \%$ of infertility. It affects approximately $7 \%$ of all men [2]. Common causes of infertility problems in men are abnormal sperm production or function due to undescended testicles, genetic defects, and health problems such as diabetes mellitus (DM) or infections [3]. DM is a complicated chronic metabolic disorder characterized by hyperglycemia, which often results from defects in insulin secretion,

\footnotetext{
"Address correspondence to this author at the Department of Clinical chemistry, Faculty of Medical Laboratory Science, Al-Neelain University. Khartoum, Sudan; Tel: +249912905847; E-mail: abdrabokarim@gmail.com
} 
insulin action, or both [4]. Most patients with DM are diagnosed during their reproductive age, and it is expected that male fertility problems associated with DM will dramatically rise as the number of patients with DM also rises [5]. DM may affect male reproductive function at multiple levels as a result of its effects on the endocrine non-diabetic of spermatogenesis, spermatogenesis itself or by impairing penile erection and ejaculation [5-7]. There are a number of reports in the literature examining the effects of diabetes on the sperm parameters. One of the first studies done by Delfino and colleagues (2007) [8], evaluated patients with both type 1 and type 2 DM. Semen analysis of these patients showed qualitative alteration; the most important effects concerned the kinetic properties, especially progressive motility. Sperm morphology was also significantly compromised. On the other hand, sperm concentration did not show significant differences [8]. Ali and colleagues (1993) [9] showed a highly significant increase in total sperm count and sperm concentration in patients with type 1 and type 2 DM. However, sperm motility and semen volume were lower than non-diabetics, whereas sperm morphology and the quality of sperm motility were unaffected. Another study was conducted by Mangoli E et al., (2013) [10] that showed a reduction in all semen parameters (semen volume, sperm count, motility and morphology) which had been observed in the diabetic patient group. Their study concluded that diabetic subjects had a significantly lower mean of semen volume, sperm count, motility and morphology compared with non-diabetic subjects. Thus, to assess the effects of DM on basic semen parameters among Sudanese patients with DM, we conducted this study.

\section{MATERIALS AND METHODS}

This is a retrospective case-non-diabetic study conducted during the period, January 2015 to February 2017, at Dr. Elsir Abu-Elhassan Fertility Center in Khartoum, Sudan. The study subjects were 300 males with type 2 diabetes mellitus (patients). They were diagnosed by the endocrinologist according to WHO and American Diabetes Association guidelines [11], and 300 non-diabetic apparently healthy males (non-diabetics) attending the laboratory of Dr. Elsir Abu-Elhassan Fertility Center as a routine investigation. Age was matched between the two groups. All participants were informed about the importance of the study and the consents were verbally obtained from the participants and they agreed to participate in this study.

BMI was calculated in the standard way: Weight $(\mathrm{kg})$ divided by square of height $(\mathrm{m})$. Waist and hip circumferences were measured to the nearest $0.1 \mathrm{~cm}$ using a flexible metric measuring tape with the subject in a standing position. Waist circumference was measured around the abdomen at the level of the umbilicus. WHR was calculated as waist circumference $(\mathrm{cm})$ divided by hip circumference $(\mathrm{cm})$. Semen was tested for volume, count of sperm, motility and morphology in each case as per the World Health Organization (WHO) criteria. The basic requirements for semen analysis were followed. These requirements were standardized by WHO guidelines that describe several procedures for an objective evaluation of the semen quality with diagnostic purposes. Data were analyzed using the Statistical Package for the Social Sciences (SPSS) version 21. Values were expressed as a mean and standard deviation. Independent t-test was used for comparison of different semen parameters among study groups. Chisquare test was used to determine the association of sperm motility with morphology among study groups. P-value $\leq$ 0.05 was considered as significant and all tests were done with $95 \%$ confidence intervals.

\section{RESULTS}

A total of 600 Sudanese males were enrolled in this study, 300 patients and 300 non-diabetics with a mean age of 35 and 34 years, respectively. The mean values of BMI and WHR did not differ in patients compared to non-diabetic (BMI: 24.5 for patients and 24.0 for non-diabetic, p.value 0.54), (WHR: For patients, it was 0.9, and 0.85 for nondiabetic, p.value 0.89 ). The patients included in the study mentioned that there is no family history of infertility.

The results of semen analysis (semen volume, sperm count, sperm motility and sperm morphology) for study groups are shown in Figs. (1-3). The semen volume $(\mathrm{mL})$ was significantly decreased in diabetic patients compared to nondiabetic $(2.46 \pm 1.18 \mathrm{~mL}, 2.65 \pm 1.19 \mathrm{~mL})$ respectively, p-value= 0.047 Fig. (2)). Sperm count showed no significant difference between diabetic and non-diabetic Fig. (3). The results of sperm motility and morphology among study groups are shown in Fig. (3) and 5, out of $67.3 \%$ of the patients and out of 39.9\%, 32.7\% of the non-diabetics had abnormal sperm motility and morphology respectively. The Odd Ratios (ORs) is $(1.7,5.1)$ indicated that males with diabetes may be associated with a high risk of abnormal sperm motility and morphology, respectively Fig. (3) and Fig. (4). 


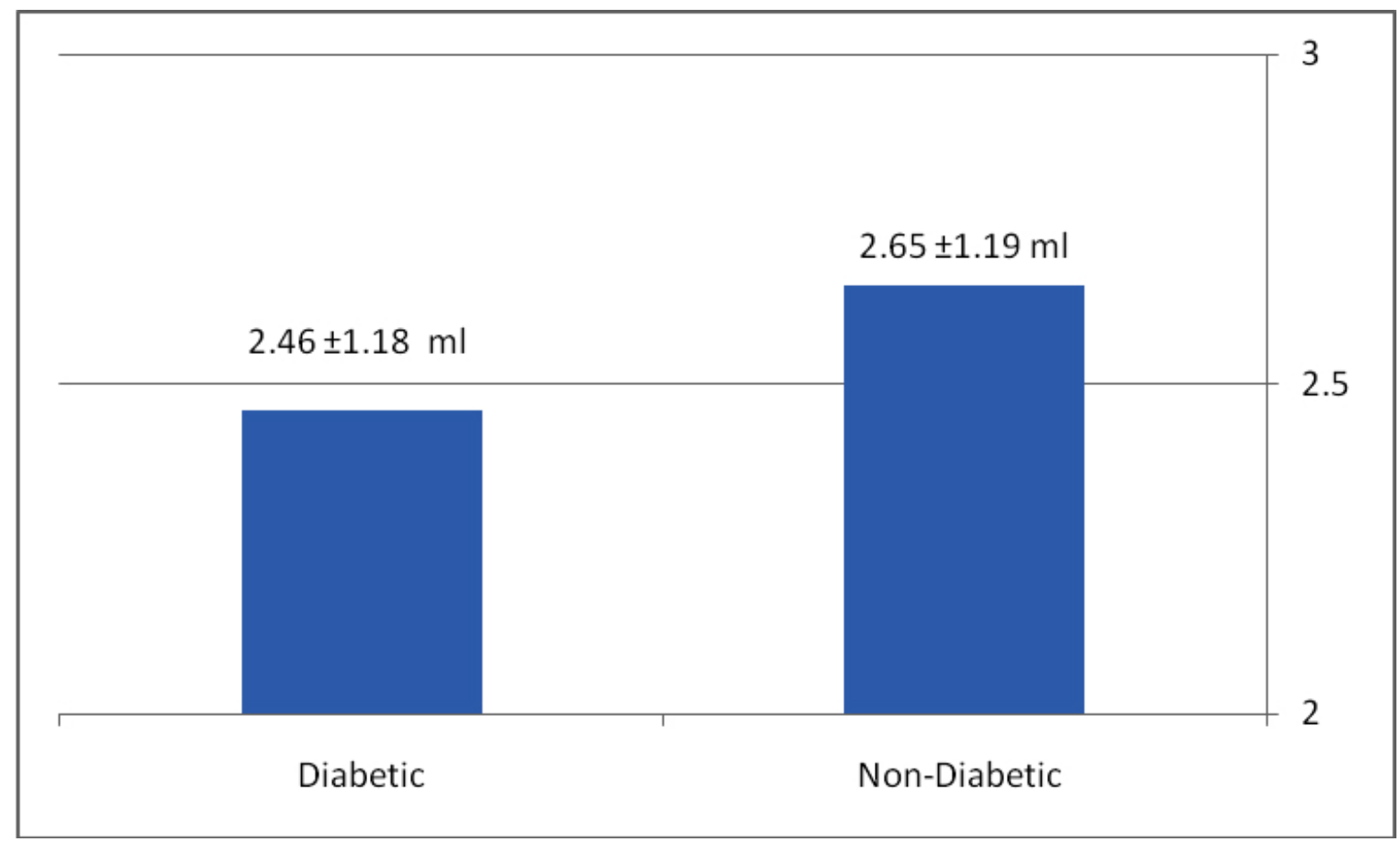

Fig. (1). Comparison of semen volume between diabetic and non-diabetic (for diabetic: $2.46 \pm 1.18 \mathrm{ml}$, for non-diabetic $2.65 \pm 1.19$ ml, p.value:0.047).

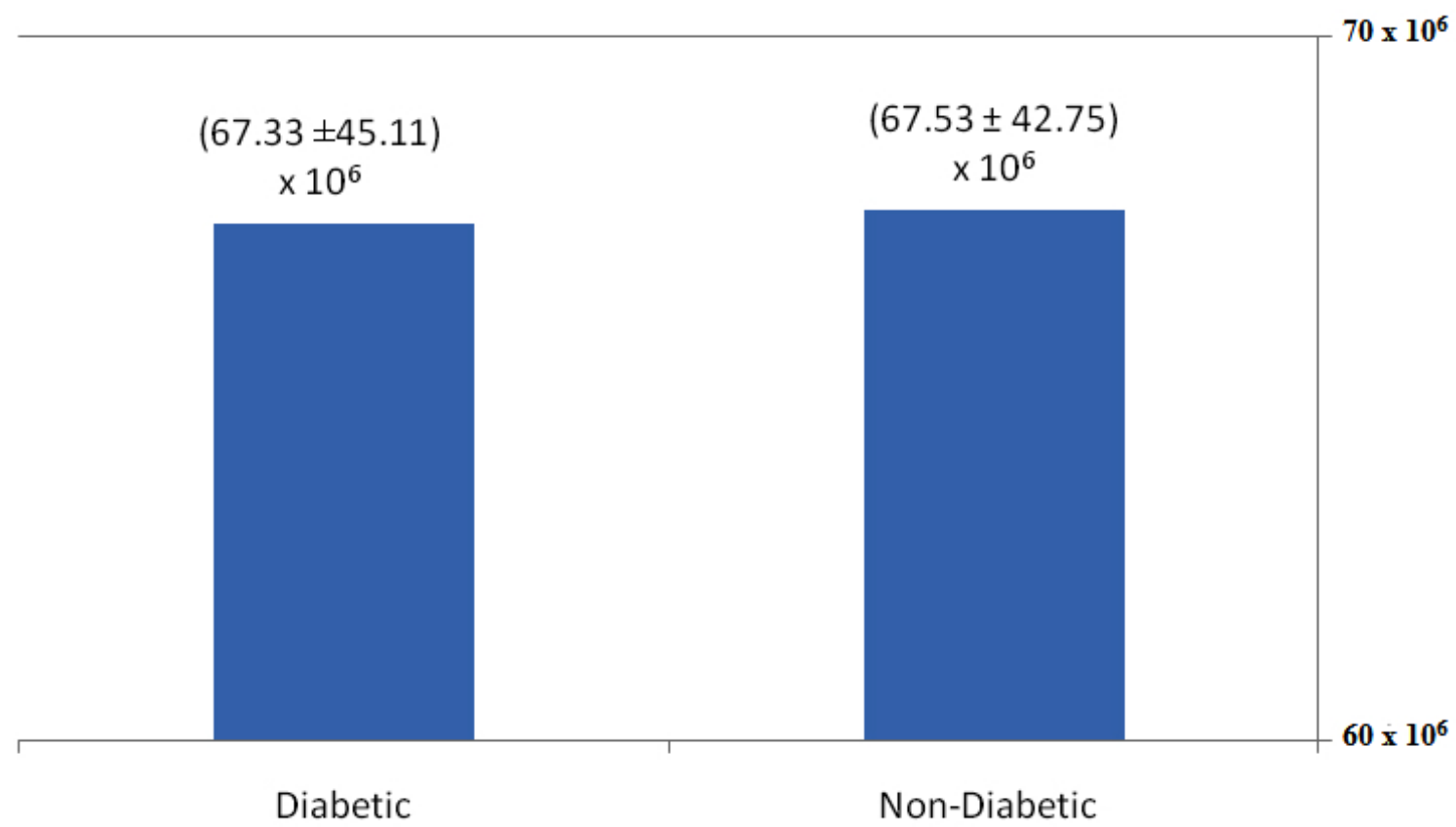

Fig. (2). Comparison of sperm count between diabetic $(67.33 \pm 45.11) \times 10^{6}$ and non-diabetic $(67.53 \pm 42.75) \times 10^{6}$, p.value: 0.954 . 


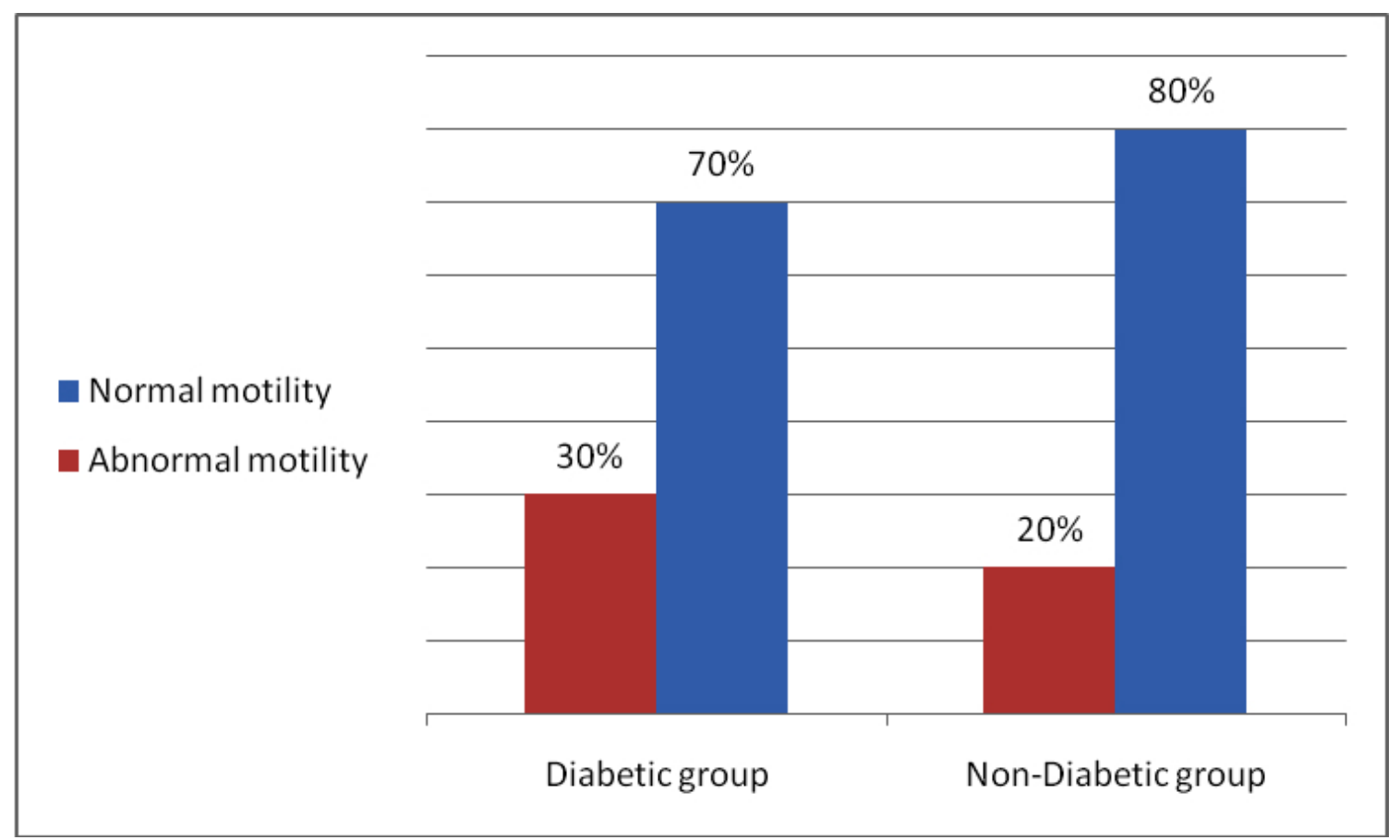

Fig. (3). Comparison of sperms motility between diabetic and non-diabetic, $80 \%$ of non-diabetic have normal sperm motility compared to 70 of diabetic, $\mathrm{P}$-value $=0.003 \mathrm{OR}=1.723 \mathrm{CI}$ lower and CI Upper (1.181-2.513).

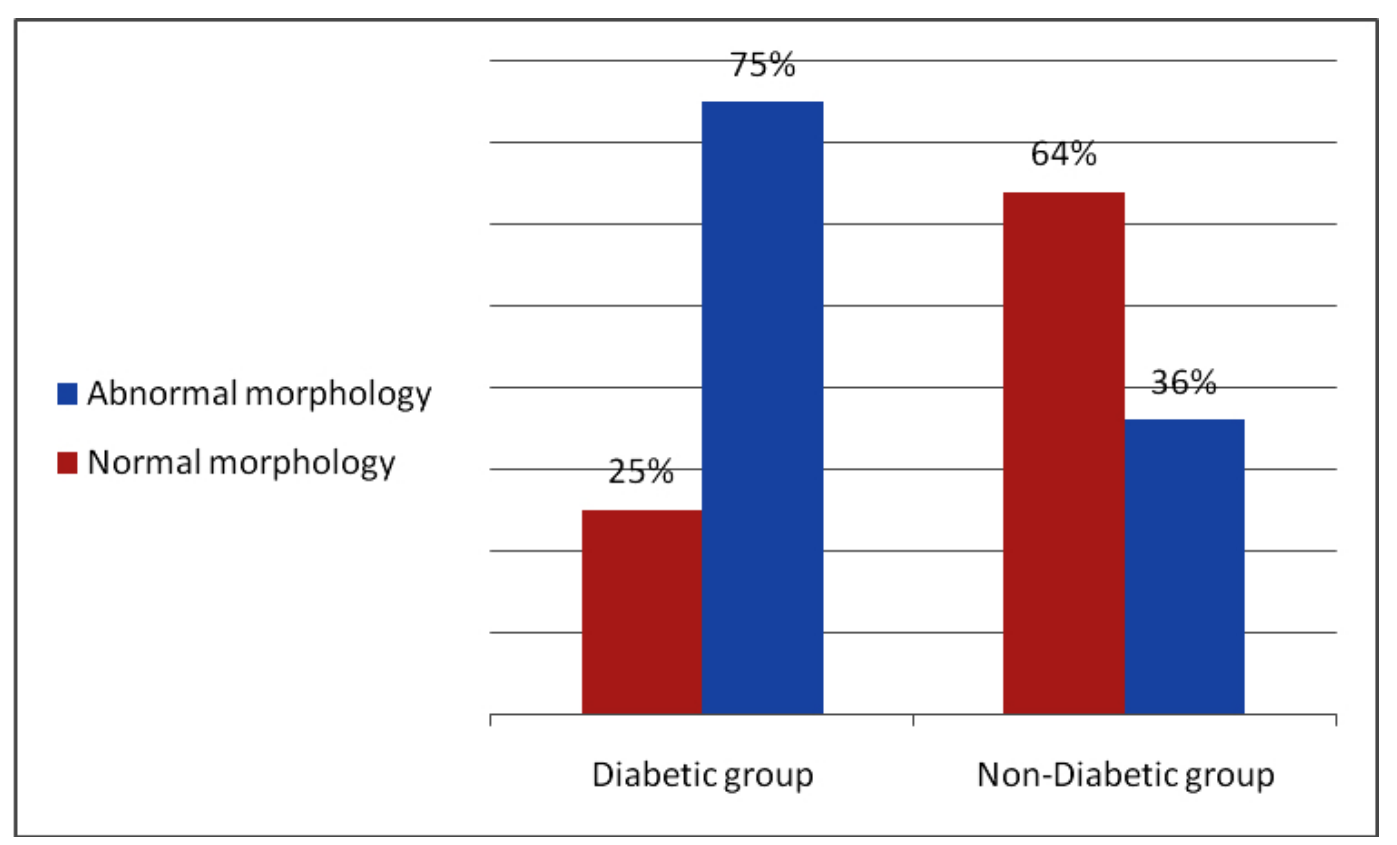

Fig. (4). Comparison of sperms morphology between diabetic and non-diabetic, $64 \%$ of non-diabetic have normal sperm morphology compared to 25 of diabetic, $\mathrm{P}$-value $=0.000 \mathrm{OR}=5.165 \mathrm{CI}$ lower and $\mathrm{CI}$ upper (3.637-7.335).

\section{DISCUSSION}

Infertility is prevalent in about $10 \%-25 \%$ of couples in their reproductive age. Of these infertility cases, $10 \%-30 \%$ are exclusively attributed to a problem of the male. Several diseases, including DM, have been implicated as contributors to deteriorating male fertility and DM has been implicated to impair the processes of male sexual acts [12].

This study has shown that Sudanese males with DM had a significant reduction in the mean of semen parameters 
(semen volume, motility and morphology of sperm) compared to the non-diabetic group. This decrease in semen quality might be as a result of hormonal alterations, or morphological changes which occur in the testis which includes an increase in the interstitial collagen, thickness of the seminiferous tubules, peritubular fibrosis, intertubular fibrosis or gonadal disorders which result from poor circulation to the testis induced by DM. A high prevalence of abnormal sperm motility and morphology was also reported before in patients with DM [12, 13]. These findings agree with Delfino et al. (2007) [8] that reported significantly lower results of the percent of normal sperm morphology and motility in diabetic patients compared to the non-diabetic group. Considering the morphology of sperms, it is a fact that the sperm cells being rapidly proliferating cells can be an easy target of damage by this oxidative stress caused by diabetes and abnormal sperm shape [14]. In fact, sperm morphology is probably the most difficult part of semen analysis to perform, and it is not easy to interpret, but the authors of this study confirmed that the part was well done according to WHO criteria, so it is suggested to conduct other studies in Sudanese with larger sample size that might be more helpful to confirm this difference. In contrast to the findings of morphology and motility, Agbaje et al. 2007 [15] reported that there is a reduction in semen volume in diabetic men compared to non-diabetics, while other semen parameters did not show a significant difference. Furthermore, diabetes was associated with increased DNA damage that may impair the reproductive capability of these men [16].

In the present study, there was no significant difference between diabetic patients and non-diabetics regarding sperm count and concentration. This finding comes in line with Delfino et al. (2007) they noted. Sperm concentration did not show significant differences between diabetic patients and non-diabetics [8]. Conversely, findings were concluded by Ali et al. (1993) [9]. They observed that there was a significant increase in total sperm count and sperm concentration in patients with type 1 and type $2 \mathrm{DM}$ in comparison to non-diabetics. Another study conducted in Sudanese males demonstrated that a significant reduction in all semen parameters (semen volume, sperm count, motility and morphology) was observed in diabetic patients when compared with non-diabetics [17]. The higher proportion of abnormal motility and abnormal morphology may be the result of poor metabolic non-diabetic, neuropathy, oxidative stress, and damage of sperm nuclear and mitochondrial DNA caused by diabetes mellitus. Our study showed that, regarding 1.7 fold, 5.2 fold higher ORs of abnormal sperm motility and morphology, respectively, diabetes may be associated with a higher risk of male infertility.

However, our study is limited by some factors. First, as most studies were based on a case-non-diabetic design, selection bias was possible. Second, semen analysis is a type of laboratory test that is difficult to standardize across different studies.

\section{CONCLUSION}

This study indicated that DM had negative effects on semen quality mainly semen volume, sperm motility and morphology. Furthermore, larger studies are needed to evaluate the causative mechanisms responsible for these changes as well as possible treatment.

\section{ETHICS APPROVAL AND CONSENT TO PARTICIPATE}

This study was approved by the ethical committee of Al-Neelain University.

\section{HUMAN AND ANIMAL RIGHTS}

No Animals were used in this research. All human research procedures followed were in accordance with the ethical standards of the committee responsible for human experimentation (institutional and national), and with the Helsinki Declaration of 1975, as revised in 2013.

\section{CONSENT FOR PUBLICATION}

Verbal consent was obtained from all the participants.

\section{CONFLICT OF INTEREST}

The authors declare no conflict of interest, financial or otherwise.

\section{ACKNOWLEDGEMENTS}

This study was supported by Dr.Elsir Abu-Elhassan Fertility Center. The authors of the study gratefully acknowledge the center for their help and support. 


\section{REFERENCES}

[1] De Neubourg D, van Duijnhoven NT, Nelen WL, D'Hooghe TM. Dutch translation of the ICMART-WHO revised glossary on ART terminology. Gynecol Obstet Invest 2012; 74(3): 233-48. [http://dx.doi.org/10.1159/000342876] [PMID: 23146953]

[2] Lotti F, Maggi M. Ultrasound of the male genital tract in relation to male reproductive health. Hum Reprod Update 2015; 21(1): 56-83. [http://dx.doi.org/10.1093/humupd/dmu042] [PMID: 25038770]

[3] Kumar N, Singh AK. Trends of male factor infertility, an important cause of infertility: A review of literature. J Hum Reprod Sci 2015; 8(4): 191-6. [http://dx.doi.org/10.4103/0974-1208.170370] [PMID: 26752853]

[4] Kharroubi AT, Darwish HM. Diabetes mellitus: The epidemic of the century. World J Diabetes 2015; 6(6): 850-67. [http://dx.doi.org/10.4239/wjd.v6.i6.850] [PMID: 26131326]

[5] Agbaje IM, Rogers DA, McVicar CM, et al. Insulin dependant diabetes mellitus: Implications for male reproductive function. Hum Reprod 2007; 22(7): 1871-7. [http://dx.doi.org/10.1093/humrep/dem077] [PMID: 17478459]

[6] Condorelli RA, La Vignera S, Mongioì LM, Alamo A, Calogero AE. Diabetes mellitus and infertility: Different pathophysiological effects in type 1 and type 2 on sperm function. Front Endocrinol (Lausanne) 2018; 9: 268. [http://dx.doi.org/10.3389/fendo.2018.00268] [PMID: 29887834]

[7] Long L, Qiu H, Cai B, et al. Hyperglycemia induced testicular damage in type 2 diabetes mellitus rats exhibiting microcirculation impairments associated with vascular endothelial growth factor decreased via PI3K/Akt pathway. Oncotarget 2018; 9(4): 5321-36. [http://dx.doi.org/10.18632/oncotarget.23915] [PMID: 29435181]

[8] Delfino M, Imbrogno N, Elia J, Capogreco F, Mazzilli F. Prevalence of diabetes mellitus in male partners of infertile couples. Minerva Urol Nefrol 2007; 59(2): 131-5. [PMID: 17571048]

[9] Ali ST, Shaikh RN, Siddiqi NA, Siddiqi PQ. Semen analysis in insulin-dependent/non-insulin-dependent diabetic men with/without neuropathy. Arch Androl 1993; 30(1): 47-54. [http://dx.doi.org/10.3109/01485019308988368] [PMID: 8420505]

[10] Mangoli E, Talebi AR, Anvari M, Pourentezari M. Effects of experimentally-induced diabetes on sperm parameters and chromatin quality in mice. Iran J Reprod Med 2013; 11(1): 53-60. [PMID: 24639693]

[11] Diagnosis and classification of diabetes mellitus. Diabetes Care 2014; 37(Suppl. 1): S81-90. [http://dx.doi.org/10.2337/dc14-S081] [PMID: 24357215]

[12] Jangir RN, Jain GC. Diabetes mellitus induced impairment of male reproductive functions: A review. Curr Diabetes Rev 2014 ; $10(3)$ : $147-57$. [http://dx.doi.org/10.2174/1573399810666140606111745] [PMID: 24919656]

[13] Amiri I, Karimi J, Piri H, et al. Association between nitric oxide and 8-hydroxydeoxyguanosine levels in semen of diabetic men. Syst Biol Reprod Med 2011; 57(6): 292-5. [http://dx.doi.org/10.3109/19396368.2011.621508] [PMID: 22047525]

[14] Taken K, Alp HH, Eryilmaz R, et al. Oxidative DNA damage to sperm cells and peripheral blood leukocytes in infertile men. Med Sci Monit 2016; 22: 4289-96. [http://dx.doi.org/10.12659/MSM.898631] [PMID: 27837200]

[15] Agbaje IM, Rogers DA, McVicar CM, et al. Insulin dependant diabetes mellitus: Implications for male reproductive function. Hum Reprod 2007; 22(7): 1871-7.

[http://dx.doi.org/10.1093/humrep/dem077] [PMID: 17478459]

[16] Agbaje IM, Rogers DA, McVicar CM, et al. Insulin dependant diabetes mellitus: Implications for male reproductive function. Hum Reprod 2007; 22(7): 1871-7. [http://dx.doi.org/10.1093/humrep/dem077] [PMID: 17478459]

[17] Abdullah AE MAEFMEMM. The association between male infertility and diabetes mellitus. J Pharm Biomed Sci 2014 2014 Jul; 12(4): 1097-2.

(C) 2018 Ibrahim et al.

This is an open access article distributed under the terms of the Creative Commons Attribution 4.0 International Public License (CC-BY 4.0), a copy of which is available at: https://creativecommons.org/licenses/by/4.0/legalcode. This license permits unrestricted use, distribution, and reproduction in any medium, provided the original author and source are credited. 